\title{
DIBUTYRYL CYCLIC ADENOSINE MONOPHOSPHATE ATTENUATES LUNG INJURY CAUSED BY COLD PRESERVATION AND ISCHEMIA-REPERFUSION
}

Takayuki Nakamura, MD

Toshiki Hirata, MD

Tatsuo Fukuse, MD

Mitsuhiro Ueda, MD

Shigeki Hitomi, MD

Hiromi Wada, MD

\begin{abstract}
Objective: Dibutyryl adenosine $3^{\prime}, 5^{\prime}$ cyclic monophosphate (db-cAMP) is a membrane-permeable analog of adenosine $3^{\prime}, 5^{\prime}$ cyclic monophosphate (cAMP). We examined the effect of db-cAMP against lung injury caused by cold preservation and ischemia-reperfusion. Methods: Rats were divided into three groups (each $n=6$ ) according to the presence or absence of $\mathrm{db}$-cAMP in the preservative solution and cold ischemia ( $4^{\circ} \mathrm{C}$ for 15 hours). In the fresh group, the lung was flushed with the preservative solution and reperfusion was performed immediately. In the control group and the db-cAMP group, the lung was flushed either with the solution or with a combination of the solution plus db-cAMP, respectively, and preserved at $4^{\circ} \mathrm{C}$ for 15 hours. The lung was reperfused for 60 minutes in an ex vivo rat lung perfusion model. Results: The shunt ratios of the reperfused lung in the db-cAMP group were $4.0 \% \pm 1.6 \%$ and $3.4 \% \pm 1.2 \% 10$ and 60 minutes, respectively, after the initiation of reperfusion, being as low as those in the fresh group and significantly lower than those in the control group $(p<$ 0.01 ). The wet/dry weight ratio of the lung tissue after reperfusion was $5.99 \pm 1.50$ in the db-cAMP group, which was similar to that in the fresh group $(5.45 \pm 0.23)$ and significantly lower than that in the control group $(14.20 \pm 3.43)(p<0.01)$. Electron microscopic examination showed less damage in the pulmonary arterial endothelium in the db-cAMP group. Conclusions: We conclude that db-cAMP attenuates the lung injury by cold preservation and ischemia-reperfusion, at least partly by protection of the vascular endothelium. (J Thorac Cardiovasc Surg 1997;114:635-42)
\end{abstract}

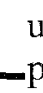
ung transplantation is an established therapeutic procedure for terminal respiratory failure. However, the duration of clinical lung preservation is limited to 10 hours, ${ }^{1}$ which is shorter than that of other parenchymal organs. Prevention of the damage caused by cold preservation and ischemia-reperfusion may help to solve the problem of the shortage of donors, which is one of the biggest issues in lung transplantation, and to improve the operative outcome. Therefore we have continued to develop a highly reliable preservative solution for the lung. ${ }^{2-7}$ In the meantime, our electron microscopic exami-

From the Department of Thoracic Surgery, Chest Disease Research Institute, Kyoto University, Kyoto, Japan.

Received for publication Jan. 30, 1997; revisions requested May 7, 1997; revisions received May 27, 1997; accepted for publication May 28, 1997.

Address for reprints: Hiromi Wada, MD, Department of Thoracic Surgery, Chest Disease Research Institute, Kyoto University, 53 Shogoin Kawahara-cho, Sakyo-ku, Kyoto, 606, Japan.

Copyright (C) 1997 by Mosby-Year Book, Inc.

$0022-5223 / 97 \$ 5.00+0 \quad \mathbf{1 2 / 1 / 8 3 5 6 1}$ nations have revealed that injury of the vascular endothelium by cold preservation is one of the factors responsible for reperfusion-induced damage. $^{2,4-7}$

Dibutyryl adenosine $3^{\prime}, 5^{\prime}$ cyclic monophosphate (dibutyryl cAMP, db-cAMP) is a membrane-permeable adenosine $3^{\prime}, 5^{\prime}$ cyclic monophosphate (cAMP) analog that is deacylated after its entry into the cell, changing to cAMP. ${ }^{8,9}$ The cAMP functions as an intracellular second messenger and has a protective effect on the vascular endothelium. Because of these features, db-cAMP has been reported to be effective in preventing lung injury induced by endotoxins, ${ }^{10}$ lipid hydroperoxides, ${ }^{11}$ oxidant gases, ${ }^{12}$ and air emboli. ${ }^{13}$ On the other hand, when attention has been focused on the damage caused by ischemia-reperfusion and organ preservation, the effectiveness of db-cAMP against injury of the heart ${ }^{14}$ and liver ${ }^{15}$ caused by cold preservation has been reported. It was also found that db-cAMP is effective against the lung injury caused by warm ischemia-reperfusion. ${ }^{16,17}$ Moreover, we have previously reported 


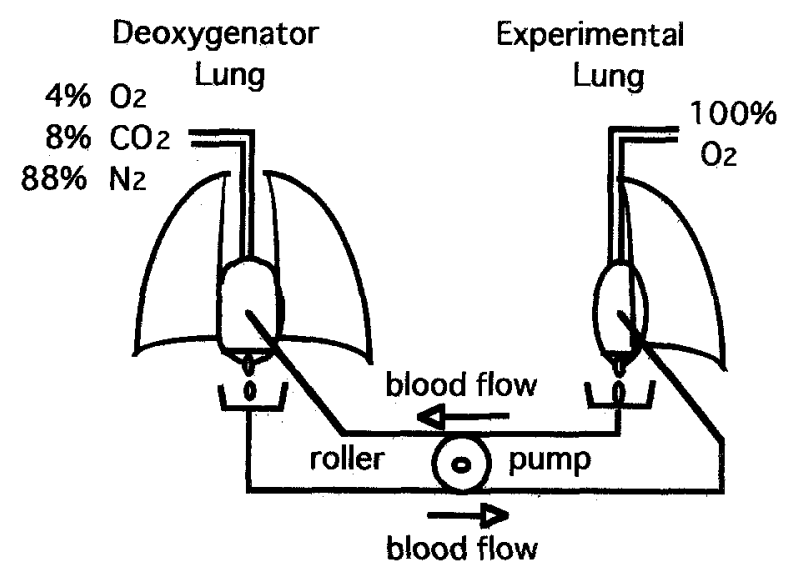

Fig. 1. Schematic representation of the perfusion model: The left lung of the experimental lung and the deoxygenator lung were ventilated with $100 \%$ oxygen and a hypoxic gas mixture (inspired oxygen fraction $=0.04$, inspired carbon dioxide fraction $=0.08$, and inspired nitrogen fraction $=0.88$ ). The circuit was filled with $40 \mathrm{ml}$ of heparinized blood drawn from three other rats. The blood deoxygenated by the deoxygenator lung was perfused through the experimental lung, oxygenated again, and then recirculated to the deoxygenator lung. This model was set up in a chamber at $37^{\circ} \mathrm{C}$ and a humidity of $100 \%$.

the protective effect of the combination use of db-cAMP, nitroglycerin, and $N$-acetylcysteine in cold lung preservation. ${ }^{5-7}$ However, no detailed reports have been published that specifically describe the effect of db-cAMP itself against lung damage caused by cold preservation and ischemia-reperfusion.

In this report, with an ex vivo isolated rat lung perfusion model, we assessed the hypothesis that the protective effect of db-cAMP on the vascular endothelium might attenuate the lung injury caused by cold preservation and ischemia-reperfusion.

\section{Materials and methods}

Donor procedure. Rats were anesthetized by an intraperitoneal injection of sodium pentobarbital $(30 \mathrm{mg} / \mathrm{kg}$ ) and intubated after tracheotomy. The animals were operated on under the following ventilation conditions with the use of a volume-controlled respirator (model SN 480-7; Shinano, Tokyo, Japan): room air, tidal volume $=$ $3.0 \mathrm{ml} / \mathrm{body}$, respiration rate $=60$ breaths $/ \mathrm{min}$, no positive end-expiratory pressure (PEEP). After a median abdominal incision, heparin (400 units) was injected into the inferior vena cava. Then a median sternotomy was performed and a 14-gauge pulmonary arterial cannula was inserted into the right ventricular outflow tract. The abdominal aorta and vena cava, the right and left ventricles, and the left atrial appendage were incised to facilitate free flow of the pulmonary venous blood. PEEP at a pressure of $2 \mathrm{~cm} \mathrm{H}_{2} \mathrm{O}$ was then applied to the airway. The pulmonary vascular bed was flushed with a perfusate $\left(4^{\circ} \mathrm{C}, 50 \mathrm{ml}\right)$ containing prostaglandin $\mathrm{E}_{1}(10 \mu \mathrm{g})$ from a height of $20 \mathrm{~cm}$. After the heart-lung block had been harvested, the pressure of the airway was kept positive at $14 \mathrm{~cm} \mathrm{H}_{2} \mathrm{O}$, the tracheal tube was clamped, and the right pulmonary hilus was ligated. The right upper and middle lobes were resected and frozen to measure cAMP levels in the lung tissue. Then the heart-lung block was immersed in the preservative solution at $4^{\circ} \mathrm{C}$.

Deoxygenator lung procedure. Anesthesia, ventilation, heparin injection, and insertion of a pulmonary arterial cannula were performed as in the donor lung procedure. The abdominal aorta and vena cava, the right and left ventricles, and the left atrial appendage were resected to facilitate free flow of the pulmonary venous blood. PEEP was applied at a pressure of $2 \mathrm{~cm} \mathrm{H}_{2} \mathrm{O}$, the tracheal tube was clamped at maximal inspiratory capacity, and the heart-lung block was harvested. Lungs of both sides were used as deoxygenators.

Reperfusion. Reperfusion of the experimental rat lung was performed in an ex vivo rat lung perfusion model at $37^{\circ} \mathrm{C}$ in a chamber at a humidity of $100 \%$ for 60 minutes. This model was originally established by Decampos and associates $^{18}$ and was described previously. We have confirmed its effectiveness and have presented an experiment using this model. ${ }^{7}$ The circuit was filled with $40 \mathrm{ml}$ of heparinized blood drawn from three other rats, which were put to death separately. The blood was kept at a temperature of $37^{\circ} \mathrm{C}$. The right lower and mediastinal lobes of the experimental lung were resected immediately before reperfusion, and the lower lobe was used for measurement of cAMP level in the lung tissue and the mediastinal lobe for transmission electron microscopic examination.

The left lung was ventilated under the following conditions: inspired oxygen fraction $=1.0$, tidal volume $=1.5$ $\mathrm{ml} /$ body, respiration rate $=40$ breaths $/ \mathrm{min}$, and PEEP $=$ $2 \mathrm{~cm} \mathrm{H}_{2} \mathrm{O}$. The deoxygenator lung was maintained under the following ventilation conditions: mixed gas (inspired oxygen fraction $=0.04$, inspired carbon dioxide fraction $=$ 0.08 , inspired nitrogen fraction $=0.88$ ), tidal volume $=$ $3.0 \mathrm{ml} / \mathrm{body}$, respiration rate $=60$ breaths $/ \mathrm{min}$, and PEEP $=2 \mathrm{~cm} \mathrm{H}_{2} \mathrm{O}$. The blood deoxygenated by the deoxygenator lung was perfused through the experimental lung, oxygenated again, and then recirculated to the deoxygenator lung. The flow rate of perfusion was gradually increased to $4 \mathrm{ml} / \mathrm{min}$ in the initial 10 minutes and, with a roller pump (model No. 7553-80; Cole Parmer Instrument Co., Chicago, Ill:), it was kept at $4 \mathrm{ml} / \mathrm{min}$ thereafter until the end of the experiment (Fig. 1). The pH value of the perfused blood was adjusted with sodium bicarbonate, if necessary, so as to keep the pH of the blood returning from the deoxygenator lung between 7.35 and 7.45 .

When severe pulmonary edema of the experimental lung occurred and water exuded from the tracheal tube, reperfusion was discontinued.

Experimental groups, Male Louis rats weighing about $300 \mathrm{gm}$ were used in the experiments. They were divided into three groups (each $n=6$ ) according to the presence or absence of additional db-cAMP in the preservative 
Table I. Data on perfused blood and deoxygenator lung

\begin{tabular}{|c|c|c|c|}
\hline & Fresh group & Control group & $d b-c A M P$ group \\
\hline \multicolumn{4}{|c|}{ Hemoglobin in circulating blood (gm/dl) } \\
\hline Before & $11.5 \pm 1.2$ & $10.9 \pm 0.6$ & $11.2 \pm 1.2$ \\
\hline \multicolumn{4}{|c|}{$\mathrm{PO}_{2}$ of blood drained from deoxygenator lung ( $\mathrm{mm} \mathrm{Hg}$ ) } \\
\hline Before & $39.3 \pm 5.9$ & $40.6 \pm 4.2$ & $37.0 \pm 7.4$ \\
\hline $10 \mathrm{~min}$ & $40.0 \pm 1.3$ & $39.6 \pm 3.0$ & $39.4 \pm 4.2$ \\
\hline $20 \mathrm{~min}$ & $40.6 \pm 1.9$ & $38.3 \pm 2.3$ & $41.4 \pm 2.4$ \\
\hline $30 \mathrm{~min}$ & $40.9 \pm 2.1$ & $38.7 \pm 2.3$ & $41.3 \pm 3.4$ \\
\hline $40 \mathrm{~min}$ & $40.3 \pm 1.9$ & $39.3 \pm 1.7$ & $41.9 \pm 2.6$ \\
\hline $50 \mathrm{~min}$ & $40.3 \pm 2.3$ & $39.4 \pm 2.4$ & $41.4 \pm 2.7$ \\
\hline $60 \mathrm{~min}$ & $40.0 \pm 2.3$ & $38.3 \pm 3.2$ & $41.5 \pm 1.8$ \\
\hline \multicolumn{4}{|c|}{$\mathrm{PCO}_{2}$ of blood drained from deoxygenator lung $(\mathrm{mm} \mathrm{Hg})$} \\
\hline Before & $40.8 \pm 7.2$ & $39.4 \pm 3.9$ & $42.0 \pm 5.0$ \\
\hline $10 \mathrm{~min}$ & $45.5 \pm 3.4$ & $43.3 \pm 3.7$ & $45.7 \pm 4.4$ \\
\hline $20 \min$ & $48.0 \pm 1.9$ & $45.9 \pm 2.9$ & $44.8 \pm 3.7$ \\
\hline $30 \mathrm{~min}$ & $45.2 \pm 5.4$ & $45.7 \pm 3.6$ & $46.4 \pm 4.7$ \\
\hline $40 \mathrm{~min}$ & $46.0 \pm 2.2$ & $45.4 \pm 5.1$ & $45.8 \pm 4.8$ \\
\hline $50 \mathrm{~min}$ & $45.1 \pm 2.8$ & $42.9 \pm 4.8$ & $47.1 \pm 5.3$ \\
\hline $60 \mathrm{~min}$ & $44.8 \pm 2.2$ & $44.3 \pm 2.7$ & $44.9 \pm 4.8$ \\
\hline
\end{tabular}

The hemoglobin level of the priming blood in the circuit showed no difference among the three groups. There was no significant difference among the groups in the blood gas analysis data of the pulmonary venous blood drained from the deoxygenator lung before and throughout reperfusion. $\mathrm{PO}_{2}$, Oxygen tension; $\mathrm{PCO}_{2}$, carbon dioxide tension.

solution and cold ischemia $\left(4^{\circ} \mathrm{C}, 15\right.$ hours). The rats in the fresh group received pulmonary flushing only with the solution, followed directly by reperfusion of the left lung for 60 minutes. The lungs were flushed with the solution alone or with the solution plus db-cAMP $(2 \mathrm{mmol} / \mathrm{L})$ in the control and the db-cAMP groups, respectively. In these two groups, the lungs were immersed in the solution used for flushing for 15 hours at $4^{\circ} \mathrm{C}$, followed by reperfusion.

Preservative solution and drugs. The solution used in these experiments was an organ preservative solution with the ionic composition of extracellular fluid and nonreducing disaccharide trehalose, which has a cell membraneprotecting effect. ${ }^{19,20}$ The solution had the following composition: $\mathrm{Na}^{+} 100 \mathrm{mmol} / \mathrm{L}, \mathrm{K}^{++} 44 \mathrm{mmol} / \mathrm{L}$, gluconate $100 \mathrm{mmol} / \mathrm{L}$, phosphate $25 \mathrm{mmol} / \mathrm{L}$, trehalose $4.1 \%$, hydroxyethyl starch $3 \%$, osmolarity $366 \mathrm{mOsm} / \mathrm{L}$, and $\mathrm{pH} 7.40$.

The db-cAMP was kindly provided by Dai-Ichi Pharmaceutical Co., Ltd., Tokyo, Japan, and prostaglandin $\mathrm{E}_{1}$ by Ono Pharmaceutical Industrial Co., Ltd., Osaka, Japan.

Physiologic evaluation. The pulmonary venous blood of the experimental lung or deoxygenator lung coming from the incised left atrium and ventricle were collected for blood gas analysis. Analyses were performed immediately before and every 10 minutes after the start of reperfusion until the end of reperfusion, with an automatic blood gas analyzer (ABL300; Radiometer A/S, Copenhagen, Denmark). The data were used to calculate the pulmonary shunt ratio (Qs/Qt), with the following formula: Os $/ \mathrm{Ot}(\%)=(\mathrm{Cc}-\mathrm{Ca}) /(\mathrm{Cc}-\mathrm{Cv}) \times 100$, where $\mathrm{Cc}, \mathrm{Ca}$, and $\mathrm{Cv}$ represent the oxygen content in the blood of the pulmonary capillary, pulmonary artery, and pulmonary vein, respectively. The peak airway pressure and mean pulmonary arterial pressure were monitored contin- uously and recorded at 10 -minutes intervals with a pressure-monitoring system (AP-641G; Nihon Kohden, Tokyo, Japan). The lower one third of the left lung was resected at the end of reperfusion and the wet tissue was weighed. Then it was dried at $55^{\circ} \mathrm{C}$ for 72 hours, the dry tissue was weighed, and the wet/dry weight ratio of the lung tissue (W/D ratio) was calculated. For assessment of the stability of the experimental system, the W/D ratio of the left lung tissue of the deoxygenator was similarly calculated.

Lung tissue cAMP level. As stated earlier, the right upper and middle lobes were resected directly after flushing and the right lower lobe directly before reperfusion, and the cAMP level in the lung tissues was measured. The tissues were frozen quickly with liquid nitrogen after removal and stored at $-80^{\circ} \mathrm{C}$ until measurement. The samples were homogenized with ice-cooled $6 \%$ trichloroacetic acid $(2 \mathrm{ml})$. After centrifugation, trichloroacetic acid was removed with ether from the supernatant. Then the samples were measured by immunoassay with a radioimmunoassay kit (cAMP Kit; Yamasa, Chiba, Japan). The protein content was quantified by the method of Lowry and coworkers. ${ }^{21}$

Light microscopic examination. The tissue samples that were freeze-preserved with liquid nitrogen at the end of reperfusion were stained for histologic examination by hematoxylin and eosin. Also, an immunohistochemical study was conducted with anti-rat granulocyte antibody (BMA T-3105); ten visual fields were randomly selected at $\times 200$ magnification from each sample, and the total granulocyte count in the visual fields was compared among the groups.

Transmission electron microscopic examination. The right mediastinal lobe was harvested directly before reperfusion and the tissue was fixed in $2.5 \%$ glutaraldehyde. Endothelial cells of the fine (about $100 \mathrm{~nm}$ in diameter) 


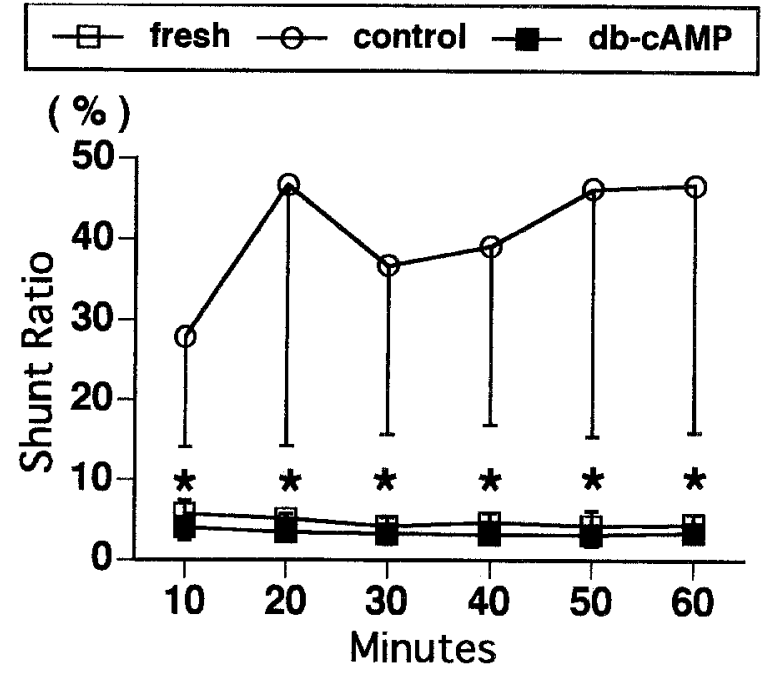

Fig. 2. Pulmonary shunt ratio: The pulmonary shunt ratio in the db-cAMP group was as low as that in the fresh group. The shunt ratio in the control group was signifcantly higher than in the db-cAMP group or the fresh group throughout the experiment, being $46.8 \% \pm 30.8 \%$ at the end of reperfusion. * $p<0.01$, fresh and $\mathrm{db}-\mathrm{cAMP}$ versus control.

pulmonary arteries were examined by transmission electron microscopy (original magnification $\times 5000$ ).

Statistical analysis. All the numeric values in the text, figures, and table are expressed as the mean \pm standard deviation. Statistical significance was evaluated by analysis of variance, Scheffe's multiple comparison test, and paired $t$ test. A $p$ value $<0.05$ was considered significant. These analyses were performed with the use of StatView J-4.02 (Abacus Concepts Inc., Berkeley, Calif).

Animal treatment. All animals received humane care in compliance with the "Guide for the Care and Use of Laboratory Animals" prepared by the Institute of Laboratory Animal Resources and published by the National Institutes of Health (NIH Publication No. 86-23, revised 1985).

\section{Results}

The data on perfused blood and deoxygenator lung. The hemoglobin level of the priming blood of the circuit showed no difference among the three groups. No significant difference was apparent among the three groups in the blood gas analysis data of the pulmonary venous blood drained from the deoxygenator lung before and throughout the reperfusion (Table I). The W/D ratio of the deoxygenator lung at the end of reperfusion was $5.17 \pm$ 0.16 in the fresh group, $5.03 \pm 0.25$ in the control group, and $5.22 \pm 0.32$ in the db-cAMP group, which showed no evidence of injury. Thus the stability of the experimental system was confirmed.

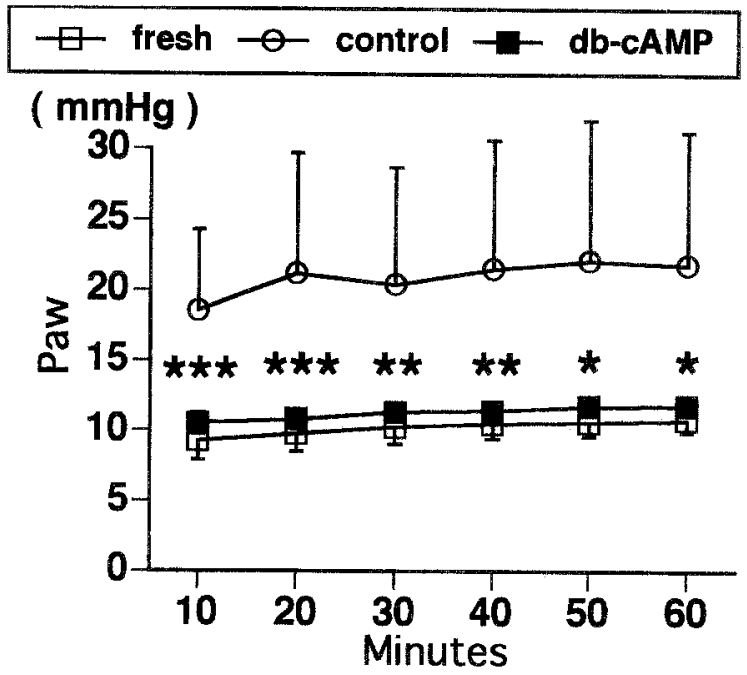

Fig. 3. Peak airway pressure (Paw): Throughout the experiment, peak airway pressure in the db-cAMP group and in the fresh group was significantly lower than in the control group. $\left({ }^{* *} p<0.01\right.$, fresh and db-cAMP vs control; ${ }^{* *} p<$ 0.01 , fresh vs control, $p=0.02$, db-cAMP vs control; * $p=$ 0.01 , fresh vs control, $p=0.02$, db-cAMP vs control).

Number of completed experiments. In the fresh group and the db-cAMP group, reperfusion was successfully achieved for 60 minutes in all experiments. However, in the control group, reperfusion was possible for 60 minutes in five experiments, but it was discontinued 20 minutes after the initiation of reperfusion in one experiment because of severe pulmonary edema.

Pulmonary shunt ratio. The pulmonary shunt ratios were very low in the db-cAMP group: $4.0 \% \pm$ $1.6 \%, 3.4 \% \pm 1.1 \%, 3.2 \% \pm 1.3 \%, 3.1 \% \pm 1.1 \%$, $3.1 \% \pm 1.4 \%$, and $3.4 \% \pm 1.2 \%$ at $10,20,30,40,50$, and 60 minutes after the start of reperfusion, respectively. These values were similar to those in the fresh group $(5.7 \% \pm 1.7 \%, 5.1 \% \pm 0.6 \%, 4.2 \% \pm 1.1 \%$, $4.7 \% \pm 1.1 \%, 4.3 \% \pm 1.9 \%$, and $4.5 \% \pm 1.2 \%$, respectively). On the other hand, the shunt ratios in the control group were $27.8 \% \pm 13.8 \%, 46.8 \% \pm$ $32.6 \%, 36.7 \% \pm 21.1 \%, 39.2 \% \pm 22.3 \%, 46.3 \% \pm$ $30.8 \%$, and $46.8 \% \pm 30.8 \%$, respectively. Thus the pulmonary shunt ratios in the db-cAMP and in the fresh group were significantly lower than those in the control group throughout the experiment $(p<$ 0.01) (Fig. 2).

Peak airway pressure. Throughout the experiment, peak airway pressures in the db-cAMP group were low: $10.5 \pm 0.7,10.8 \pm 0.7,11.3 \pm 0.6,11.4 \pm$ $0.7,11.7 \pm 0.5$, and $11.8 \pm 0.6 \mathrm{~mm} \mathrm{Hg}$ at $10,20,30$, 


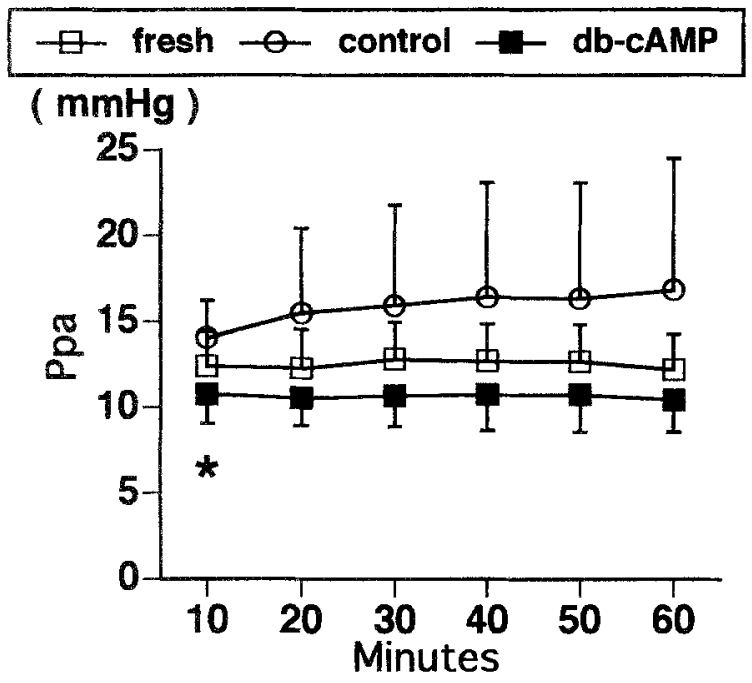

Fig. 4. Mean pulmonary arterial pressure (Ppa): Mean pulmonary arterial pressure in the db-cAMP group 10 minutes after the initiation of reperfusion was significantly lower than in the control group. Thereafter, mean pulmonary arterial pressure tended to be lower in the db-cAMP group until the end of the experiment, but there was no significant difference among the three groups $\left({ }^{*} p=0.04\right.$, db-cAMP vs control).

40,50 , and 60 minutes after the start of reperfusion, respectively. These values were identical to those in the fresh group $(9.3 \pm 1.4,9.8 \pm 1.3,10.2 \pm 1.2$, $10.5 \pm 1.1,10.6 \pm 0.9$, and $10.8 \pm 0.9 \mathrm{~mm} \mathrm{Hg}$, respectively). Peak airway pressures in the control group were $18.6 \pm 5.7,21.2 \pm 8.5,20.4 \pm 8.3,21.5 \pm$ $9.1,22.1 \pm 10.0$, and $21.8 \pm 9.4 \mathrm{~mm} \mathrm{Hg}$, respectively. Thus, throughout the experiment, peak airway pressures in the db-cAMP and in the fresh groups were significantly lower than those in the control group (after 10 and 20 minutes: $p<0.01$, fresh and db-cAMP vs control; after 30 and 40 minutes: $p<$ 0.01 , fresh vs control, $p=0.02, \mathrm{db}$-cAMP vs control; after 50 and 60 minutes: $p=0.01$, fresh vs control, $p=0.02$, db-cAMP vs control) (Fig. 3).

Mean pulmonary arterial pressure. Mean pulmonary arterial pressure 10 minutes after the start of reperfusion was $14.0 \pm 2.2 \mathrm{~mm} \mathrm{Hg}$ in the control group and $10.8 \pm 1.7 \mathrm{~mm} \mathrm{Hg}$ in the db-cAMP group, and the difference between the two groups was significant $(p=0.04)$. Thereafter, mean pulmonary arterial pressure showed a tendency to increase in the control group until the end of the experiment, but no significant difference was detected among the three groups (Fig. 4).

W/D ratio. W/D ratio at the end of reperfusion was $5.45 \pm 0.23$ in the fresh group, $14.20 \pm 3.43$ in
Nakamura et al. 639

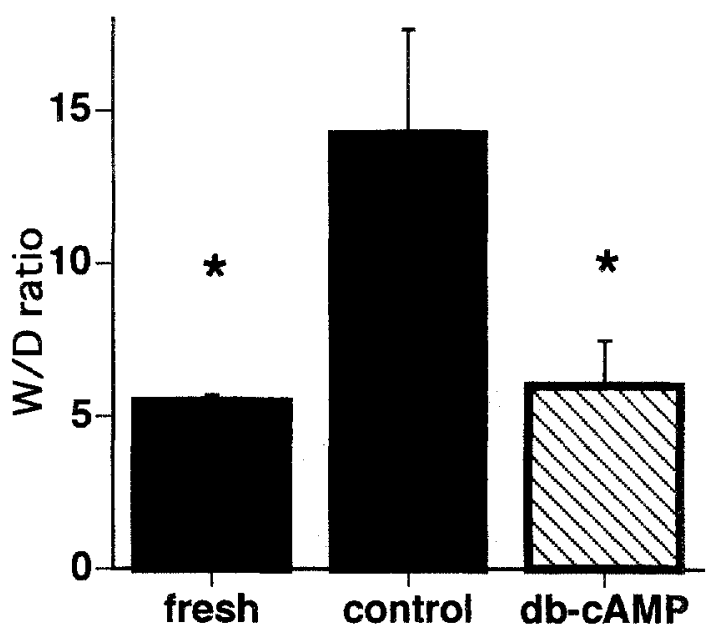

Fig. 5. W/D ratio: The W/D ratio at the end of reperfusion was $5.45 \pm 0.23$ in the fresh group, $14.20 \pm 3.43$ in the control group, and $5.99 \pm 1.50$ in the db-cAMP group; it was significantly $\left({ }^{*} p<0.01\right)$ lower in the db-cAMP and fresh groups than in the control group.

the control group, and $5.99 \pm 1.50$ in the db-cAMP group, significantly lower in the db-cAMP and fresh groups than in the control group $(p<0.01)$ (Fig. 5).

Lung tissue cAMP level. The cAMP level in the lung tissue was $15.0 \pm 6.8 \mathrm{pmol} / \mathrm{mg}$ protein immediately after flushing and $12.3 \pm 4.4 \mathrm{pmol} / \mathrm{mg}$ protein before reperfusion in the control group; thus no significant difference was detected before and after preservation.

Light microscopic examination. Histologic study with hematoxylin and eosin stain revealed almost normal findings of the lung tissue after reperfusion in the db-cAMP group and in the fresh groups. On the contrary, in the control group, marked edema was present around the blood vessels in the lung tissue after reperfusion.

In the immunohistochemical study with anti-rat granulocyte antibody, the total granulocyte count in ten visual fields was zero to two cells in each group, indicating almost no infiltration of granulocytes during reperfusion.

Transmission electron microscopic examination. Examination by transmission electron microscopy of the fine pulmonary arterial endothelium after preservation revealed almost normal endothelium in the fresh group (Fig. 6, $A$ ). In the control group, however, detachment of the endothelial cells from the basal lamina were observed, indicating apparent damage of the pulmonary vascular endothelium (Fig. $6, B$ ). On the other hand, in the db-cAMP 

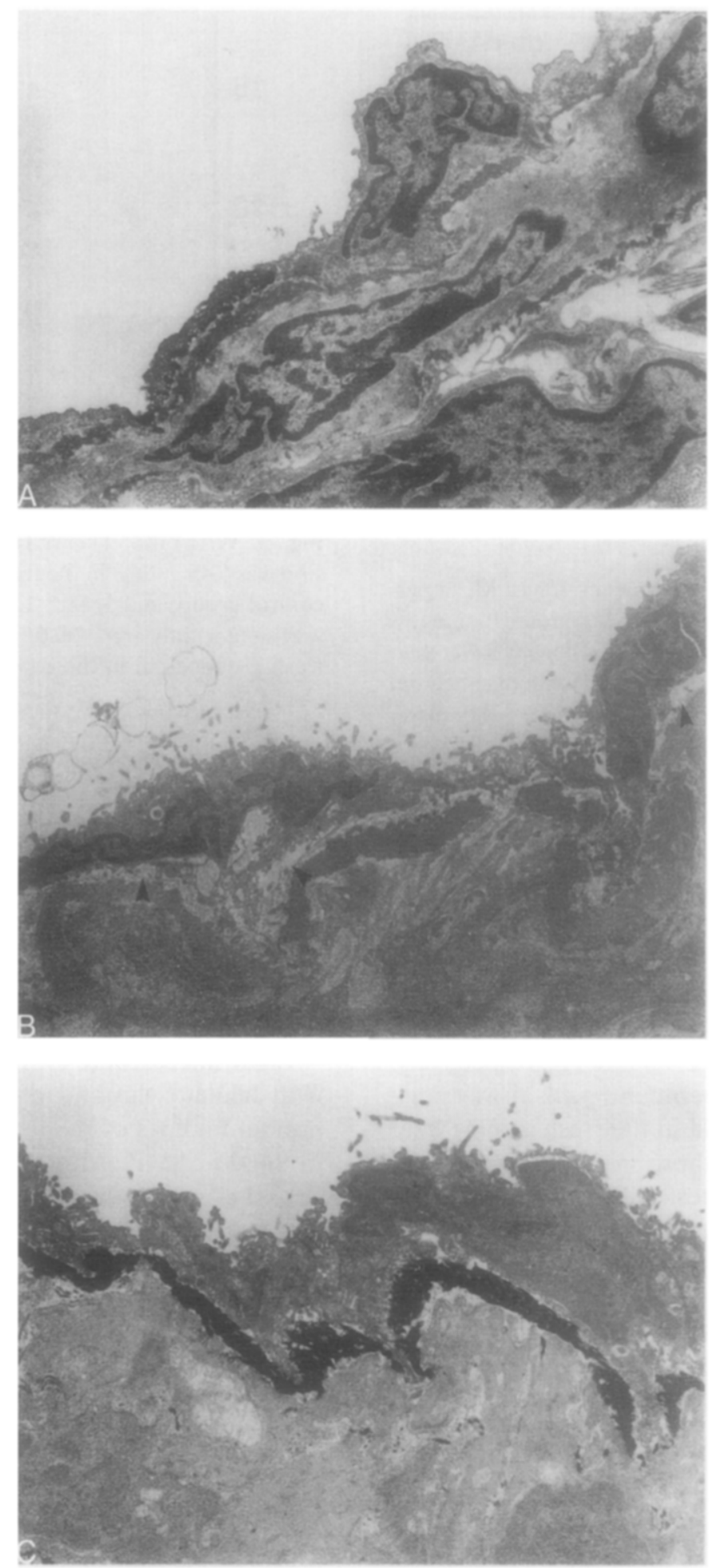

Fig. 6. Transmission electron microscopic examination (original magnification $\times 5000$ ): The pulmonary arterial endothelium after preservation looked almost normal in the fresh group (A). In the control group (B), there was detachment of endothelial cells from the basal lamina (arrowheads), indicating damage of vascular endothelium. In the $\mathrm{db}$-cAMP group $(\mathrm{C})$, the endothelial cells were satisfactorily preserved, showing the protective effect of db-cAMP. 
group, the endothelial cells were as satisfactorily preserved as in the fresh group, showing the protective effect of db-cAMP (Fig. 6, C).

\section{Discussion}

In the present experiment, we investigated the effectiveness of db-cAMP, which elevates the intracellular cAMP level, against the lung injury induced by cold preservation and ischemia-reperfusion. A cell membrane-permeable cAMP analog, db-cAMP is deacylated after its entry into the cells and changes to cAMP. ${ }^{8,9}$ Furthermore, db-cAMP and its metabolite $N^{6}$-monobutyryl cAMP have an inhibitory effect on cAMP phosphodiesterase, thereby elevating the intracellular cAMP level, ${ }^{22}$

It has been reported that cAMP has a protective effect on the vascular endothelium as an intracellular second messenger, and therefore its analog dbcAMP is effective against endotoxins, ${ }^{10}$ lipid hydroperoxides, ${ }^{11}$ oxidant gases, ${ }^{12}$ air emboli, ${ }^{13}$ cold preservation of the heart ${ }^{14}$ and liver, ${ }^{15}$ and lung damage resulting from warm ischemia-reperfusion. ${ }^{16,17}$ In addition, the combination use of $\mathrm{db}$ cAMP, nitroglycerin, and $N$-acetylcysteine has been proved effective in cold lung preservation. ${ }^{5-7}$ However, no detailed investigations have so far been conducted on the effect of db-cAMP itself against the lung damage resulting from cold preservation and ischemia-reperfusion.

In our current study, lungs flushed with the solution containing db-cAMP showed excellent function equivalent to that of fresh lungs during reperfusion after cold preservation for 15 hours.

Electron microscopy showed less damage of the pulmonary arterial endothelium in the db-cAMP group than in the control group in specimens harvested before reperfusion, indicating the protective effect of db-cAMP on the vascular endothelium. Moreover, on macroscopic examination of the color and homogeneity of perfusion and ventilation, the lungs of the db-cAMP group showed more satisfactory pulmonary function even at an extremely early stage (within 5 minutes after the start of reperfusion) than did the control lungs. These results suggest that the protective effect of db-cAMP against lung injury caused by cold preservation and ischemia-reperfusion can be attributed, at least in part, to suppression of vascular endothelial damage during lung preservation.

The protective effect of cAMP on the vascular endothelium is said to result from its three actions: suppression of vascular permeability, ${ }^{10-13,} 16,17,23,24$ relaxation of vascular smooth muscle, ${ }^{11,17}$ and suppression of adhesion of neutrophils to the vascular wall. ${ }^{14,25}$ In our immunohistochemical experiment, however, granulocyte adhesion to the vascular wall and infiltration into the tissue were almost absent in all the groups. Consequently, it appears less likely that suppression of granulocyte adhesion to the vascular wall by db-cAMP contributed to its protective effect. On the other hand, the direct measurement of vascular permeability and degree of contraction of the smooth muscle cells was impossible in our experimental model. It is therefore necessary to conduct further investigations on the mechanism of the protective effect of db-cAMP on the vascular endothelium.

Ischemia of vascular endothelial ${ }^{23}$ and smooth muscle cells ${ }^{14}$ lowers the intracellular cAMP level by decreasing adenylate cyclase activity ${ }^{23}$ and increasing phosphodiesterase activity. ${ }^{14}$ In the current experiment, the content of cAMP in lung tissue tended to decrease in the control group during cold preservation, but the change was not significant (in the db-cAMP group, the cAMP level in the lung tissue could not be measured because of cross reaction problems on immunoassay). Because lung tissue is composed of various cells, we cannot deny that the level of CAMP in the tissue does not reflect the amount of cAMP in the vascular endothelial cells and smooth muscle cells. However, it may also be assumed that the cold ischemic state decreases tissue metabolism and, accordingly, the cAMP level does not change significantly.

It is widely accepted that db-cAMP elevates the intracellular level of cAMP. We assume that in the current experimental model db-cAMP also raised the cAMP level in the vascular endothelial cells and smooth muscle cells of the lung, thereby producing a protective effect.

In conclusion, db-cAMP, which elevates the intracellular level of cAMP as a second messenger, attenuates the lung injury caused by cold preservation and ischemia-reperfusion. The scanning electron microscopic findings indicated that such a protective effect may be due partly to the protective effect of db-cAMP on the vascular endothelium. Further studies are required to elucidate the details of the mechanism of this protective effect of db-cAMP.

\section{REFERENCES}

1. Cooper JD. Current status of lung transplantation. Transplant Proc 1991;23:2107-14.

2. Bando T, Kosaka S, Liu CJ, Hirai T, Hirata T, Yokomise H, 
et al. Effects of newly developed solutions containing trehalose on twenty-hour canine lung preservation. J Thorac Cardiovasc Surg 1994;108:92-8.

3. Liu CJ, Bando T, Hirai T, Hirata T, Yagi K, Yokomise H, et al. Improved 20 -hour canine lung preservation with a new solution-ET-Kyoto solution. Eur J Cardiothorac Surg 1995; 9:548-52.

4. Wada H, Fukuse T, Nakamura T, Liu CJ, Bando T, Kosaka $\mathrm{S}$, et al. ET-Kyoto solution for 48-hour canine lung preservation. Ann Thorac Surg 1996;61:963-8.

5. Wada H, Liu CJ, Hirata T, Bando T, Kosaka S. Effective 30-hour preservation of canine lungs with modified ETKyoto solution. Ann Thorac Surg 1996;61:1099-105.

6. Liu CJ, Ueda M, Kosaka S, Hirata T, Fukuse T, Yokomise H, et al. A newly developed solution enhances thirty-hour preservation in a canine lung transplantation model. J Thorac Cardiovasc Surg 1996;112:569-76.

7. Fukuse T, Hirata T, Ueda M, Hitomi S, Wada H. Effects of Euro-Collins, University of Wisconsin, and new extracellulartype trehalose-containing Kyoto solutions in an ex vivo rat lung preservation model. Transplantation 1996;62:1212-7.

8. Falbriad JG, Posternak T, Sutherland EW. Preparation of derivatives of adenosine $3^{\prime}, 5^{\prime}$-phosphate. Biochim Biophys Acta 1967;148:99-105.

9. Kaukel E, Hilz H. Permeation of dibutyryl cAMP into HeLa cells and its conversion to monobutyryl cAMP. Biochem Biophys Res Commun 1972;46:1011-8.

10. Chang S, Sakai A, Voelkel NF. Dibutyryl-cAMP blocks endotoxin-induced lung injury in rats. Am Rev Respir Dis 1989;140:1814-7.

11. Farrukh IS, Gurtner GH, Michael JR. Pharmacological modification of pulmonary vascular injury: possible role of cAMP. J Appl Physiol 1987;62:47-54.

12. Kennedy TP, Michael JR, Hoidal JR, Hasty D, Sciuto AM, Hopkins C, et al. Dibutyryl cAMP, aminophylline, and $\beta$-adrenergic agonists protect against pulmonary edema caused by phosgene. J Appl Physiol 1989;67:2542-52.

13. Kobayashi H, Kobayashi T, Fukushima M. Effects of dibutyryl cAMP on pulmonary air embolism-induced lung injury in awake sheep. J Appl Physiol 1987;63:2201-7.

14. Pinsky D, Oz M, Liao H, Morris S, Brett J, Sciacca R, et al. Restoration of the cAMP second messenger pathway en- hances cardiac preservation for transplantation in a heterotopic rat model. J Clin Invest 1993;92:2994-3002.

15. Ness KV, Podkameni D, Schwartz M, Boros P, Miller C. Dibutyryl cAMP reduces nonparenchymal cell damage during cold preservation of rat livers. J Surg Res 1995;58:728-31.

16. Seibert AF, Thompson WJ, Taylor A, Wilborn WH, Barnard $J$, Haynes J. Reversal of increased microvascular permeability associated with ischemia-reperfusion: role of cAMP. J Appl Physiol 1992;72:389-95.

17. Adkins WK, Barnard JW, May S, Seibert AF, Haynes J, Taylor AE. Compounds that increase cAMP prevent ischemia-reperfusion pulmonary capillary injury. I Appl Physiol 1992;72:492-7.

18. Decampos KN, Keshavjee SH, Tremblay L, Yamashiro T, Slutsky AS. Use of a hypoxic lung as a deoxygenator to provide extended assessment of pulmonary function in rats. J Appl Physiol 1996;80:1835-40.

19. Crowe JH, Crowe LM, Chapman D. Preservation of membranes in anhydrobiotic organisms: the role of trehalose. Science 1984;223:701-3.

20. Wiemken A. Trehalose in yeast: stress protectant rather than reserve carbohydrate. Antonie Van Leeuwenhoek 1990;58: 209-17.

21. Lowry O, Rosebrough N, Farr A, Randall R. Protein measurement with the Folin reagent. J Biol Chem 1951;193:265-75.

22. Hsie AW, Kawashima K, O'Neill JP, Schröder CH. Possible role of adenosine cyclic $3^{\prime}, 5^{\prime}$-monophosphate phosphodiesterase in the morphological transformation of Chinese hamster ovary cells mediated by $\mathrm{N}^{6}, 0^{2^{\prime}}$-dibutyryl adenosine cyclic 3',5'-monophosphate. J Biol Chem 1975;250:984-9.

23. Ogawa S, Koga S, Kuwabara K, Brett J, Morrow B, Morris $\mathrm{SA}$, et al. Hypoxia-induced increased permeability of endothelial monolayers occurs through lowering of cellular cAMP levels. Am J Physiol 1992;262:C546-54.

24. Stelzner TJ, Weil JV, O'Brien RF. Role of cyclic adenosine monophosphate in the induction of endothelial barrier properties. J Cell Physiol 1989;139:157-66.

25. Boxer LA, Allen JM, Baehner RL, Amick V. Diminished polymorphonuclear leukocyte adherence: function dependent on release of cyclic AMP by endothelial cells after stimulation of $\beta$-receptors by epinephrine. J Clin Invest 1980;66:268-74. 